Warsita, Bambang. (2008). Teknologi Pembelajaran dan Aplikasinya. Jakarta: Rineka Cipta.

\title{
UPAYA MENINGKATKAN HASIL BELAJAR PERMAINAN TONNIS MENGGUNAKAN MODIFIKASI MEDIA PEMBELAJARAN
}

\author{
Ahsan Hakim Fariza ${ }^{(1)}$, Rony Syaifullah ${ }^{(2)}$ \\ ${ }^{(1)}$ Universitas Sebelas Maret Surakarta \\ ${ }^{(2)}$ Universitas Sebelas Maret Surakarta
}

\begin{abstract}
The purpose of this research is to improve the learning outcomes of the tonnis game in fourth grade students in SD Negeri Banyuanyar II Surakarta in academic year 2017/2018.

This research is a Classroom Action Research (PTK). This research was conducted in two cycles, each cycle consisting of four stages: planning, implementation, observation and reflection. Subjects in Classroom Action Research are fourth grade students of SD Negeri Banyuanyar II Surakarta, amounting to 36 students consisting of 21 male students and 15 female students. Sources of data in this study were obtained from students, researchers and teachers as collaborators. Data collection techniques use tests and observations. Data validity using data triangulation technique. Data analysis using qualitative descriptive technique based on qualitative analysis percentage.

The results of the research on prasiklus stage are only 12 students who completed with the percentage $33.33 \%$ and 24 students not complete with the percentage of $66.67 \%$. First cycle obtained the results of student learning that has been completed as many as 25 students (69.44\%) and 11 students are not complete (30.56\%). The acquisition of affective averages (72.22\%), psychomotor $(58.33 \%)$ and cognitive $(77.78 \%)$. Second cycle obtained the results of student learning that has been completed as many as 28 students (77.78\%) and 8 students is not complete (22.22\%). The acquisition of affective averages (100\%), psychomotor (86.11\%) and cognitive (77.78\%). Based on the analysis results from cycle I and cycle II showed a significant increase and according to achievement targets.

Based on the research results obtained the conclusion that: Modification of learning media can improve the learning outcomes of basic motion of the game tonnis on the fourth grade students of SD Negeri Banyuanyar II Surakarta academic year 2017/2018.
\end{abstract}

Keywords : Learning Outcomes, Game Tonnis 


\section{PENDAHULUAN}

Pendidikan jasmani mempunyai banyak sekali materi untuk diajarkan yang terangkum dalam kurikulum Penjas pada tiaptiap sekolah. Salah satu materi yang diajarkan adalah permainan bola kecil tonnis. Permainan bola kecil terdapat dalam kompetensi dasar 1.1 Mempraktikkan gerak dasar dan permainan bola kecil sederhana dengan peraturan yang dimodifikasi serta nilai kerjasama, sportivitas dan kejujuran. Mungkin permainan ini masih asing bagi sebagian orang, masih banyak yang belum tahu persis seperti apa itu tonnis, bagaimana cara bermainnya, peraturannya, alatalatnya, dsb. Olahraga ini sebenarnya hampir mirip dengan tenis, hanya berbeda di ukuran lapangan, alat pemukul dan peraturan bermainnya saja. Permainan tonnis ini dapat dijadikan sebagai olahraga pendidikan, rekreasi maupun olahraga prestasi. Sebagai olahraga pendidikan, teknik dasar dalam permainan tonnis diajarkan melalui proses pembelajaran pendidikan jasmani. Permainan tonnis ini memiliki manfaat yang cukup besar dalam pembentukan individu yang sportif dan perkembangan jasmani maupun rohaninya. Perkembangan jasmani ditujukan untuk membentuk sikap tubuh yang baik meliputi anatomis, fisiologis, kesehatan serta komponen kebugaran jasmani seperti kekuatan, kelincahan, kecepatan, daya tahan, kelentukan, dsb. Manfaat bagi rohani yaitu kejiwaan, kepribadian dan karakter akan tumbuh ke arah yang sesuai dengan tuntutan masyarakat.

Tidak semua sekolah memiliki sarana dan prasarana yang dibutuhkan untuk bermain tonnis. Ada beberapa sekolah yang mencoba untuk memberikan pembelajaran permainan tonnis kepada peserta didik, namun banyak permasalahan mucul. Sarana dan prasarana yang dimiliki kurang memadai, serta pembelajaran belum menggunakan modifikasi media pembelajaran sehingga banyak siswa yang harus menunggu untuk mendapatkan giliran memakai alat karena keterbatasan alat.

Di SD Negeri Banyuanyar

II, Kecamatan Banjarsari, Kota 
Surakarta, guru Penjasorkes memberikan pembelajaran tentang tonnis pada kelas IV, pembelajaran berjalan dengan baik sebenarnya. Namun, antusiasme peserta didik kurang terfasilitasi dikarenakan kurangnya alat pembelajaran yang ada, paddle hanya ada dua, bola tonnis hanya ada 2 buah, dan lapangannya pun menggunakan lapangan sepak takraw yang garisnya sudah mulai memudar, jadi tidak jelas kelihatan ketika sedang bermain apakah bola masuk atau keluar lapangan.

\begin{tabular}{ll}
\multicolumn{2}{c}{ Banyak permasalahan } \\
muncul setelah pembelajaran \\
terlaksana, selain kekurangan alat
\end{tabular} (paddle dan bola), yaitu banyak siswa yang sulit memukul bola karena paddlenya yang kecil. Hal ini ternyata berpengaruh besar terhadap hasil belajar siswa kelas IV SD Negeri Banyuanyar II dalam permainan tonnis, dari total 36 siswa hanya 12 siswa $(33,33 \%)$ yang tuntas sedangkan sisanya 24 siswa $(66,66 \%)$ belum tuntas. Rendahnya hasil belajar ini dipengaruhi oleh beberapa faktor diantaranya kurang begitu senang dengan materi tonnis ini, penyajian materi yang itu-itu saja dan membosankan, serta kurang kreatifnya guru yang masih menggunakan alat seadanya. Untuk meningkatkan hasil belajar perlu adanya perubahan dalam proses pembelajarannya serta penambahan sarana yang mendekati bentuk aslinya agar tujuan dari pembelajaran tersebut dapat tercapai. Untuk itu seorang guru Penjasorkes harus memiliki kreatifitas dalam setiap pembelajaran yang akan disajikan. Penggunaan modifikasi media pembelajaran dapat menjadi solusi atas permasalahan kurangnya sarana yang dimiliki sekolah dan sulitnya siswa memukul bola karena ukuran paddlenya terbilang kecil.

Berdasarkan masalahmasalah yang ada diatas, dengan demikian perlu dilakukan sebuah pembelajaran yang efektif, kreatif dan efisien. Memanfaatkan sarana yang ada dan menambahkan sarana pendukung secara optimal tanpa mengesampingkan materi pokok pembelajaran yaitu untuk meningkatkan keterampilan bermain tonnis. Maka perlu dilakukan Penelitian Tindakan Kelas dengan 
judul, "Upaya Meningkatkan Hasil

Belajar Permainan Tonnis

Menggunakan Modifikasi Media

Pembelajaran Pada Siswa Kelas IV

SD Negeri Banyuanyar II Surakarta

Tahun Ajaran 2017/2018”.

\section{Tujuan Penelitian}

Berdasarkan latar belakang dan rumusan masalah yang telah disampaikan diatas, tujuan penelitian ini adalah untuk:

Meningkatkan hasil belajar permainan tonnis menggunakan modifikasi media pembelajaran pada siswa kelas IV SD Negeri Banyuanyar II Surakarta tahun ajaran 2017/2018.

\section{Kajian Pustaka}

\section{Pendidikan Jasmani}

Pendidikan jasmani terdiri dari kata pendidikan dan jasmani. Pendidikan adalah pengubahan dan tatalaku seseorang dalam usaha mendewasakan melalui upaya pengajaran dan latihan, sedangkan jasmani adalah tubuh atau badan.

Pendidikan jasmani adalah proses pendidikan melalui aktivitas jasmani, permainan atau olahraga yang terpilih untuk mencapai tujuan pendidikan. Jadi pendidikan jasmani merupakan bagian tak terpisahkan dari dunia pendidikan yang pada intinya adalah mendidik anak.

Pendidikan jasmani harus secara terus menerus sepanjang hidup manusia dengan berbagai macam pola, dan juga diberikan pada sekolah mulai dari kanak-kanak sampai perguruan tinggi. Tujuan pendidikan jasmani konsisten dengan tujuan pendidikan umum.

\section{Belajar}

Belajar dan mengajar merupakan dua konsep yang tidak dapat dipisahkan satu dengan yang lain. Belajar menunjuk pada apa yang harus dilakukan seseoran sebagai subjek yang menerima pelajaran(siswa), sedangkan mengajar menunjuk pada apa yang harus dilakukan oleh seorang guru sebagai pengajar.

Dua konsep tersebut menjadi terpadu dalam satu kegiatan, manakala terjadi interaksi antara guru dan siswa, siswa dengan siswa, dan siswa pada saat pengajaran berlangsung. Inilah makna belajar mengajar dan mengajar sebagai suatu 
proses. Interaksi guru dengan siswa sebagai makna utama proses pengajaran memegang peranan penting untuk mencapai tujuan pengajaran yang efektif.

Belajar merupakan suatu proses usaha yang dilakukan seseorang untuk memperoleh suatu perubahan yang lebih baik. Hal ini artinya, dalam kegiatan belajar terdapat ciri-ciri didalamnya.

Salah satu tugas pokok seorang guru adalah mengevaluasi taraf keberhasilan rencana elaksanaan kegiatan pembelajaran. Hasil belajar merupakan perubahan perilaku yang diperoleh siswa setelah mengalami proses belajar. Perolehan aspekaspek perubaha perilaku tersebut tergantung pada apa yang dipelajari oleh siswa.

Hasil belajar dicapai apabila terjadi perubahan yang lebih baik, baik ranah afektif, kognitif dan psikomotor. Namun untuk mencapai hasil belajar yang optimal banyak faktor yang mempengaruhinya. Nana Sudjana (2005:39) menyatakan ,"Hasil belajar yang dicapai siswa dipengaruhi oleh dua faktor utama yakni, faktor dalam diri siswa dan faktor yang datang dari luar diri siswa atau faktor lingkungan".

\section{Permainan Tonnis}

Permainan tonnis merupakan sebuah olahraga permainan bola kecil dimana dalam memainkannya dengan memadukan antara permainan badminton dan permainan tenis lapangan yang dapat dimainkan di dalam maupun di luar gedung sekolah.

Drs. H. Tri Nurharsono, M. Pd. dan Sri Haryono, S. Pd, M. Or. (2009: 5-6) menyatakan tonnis adalah jenis permainan menggunakan bola kecil dan paddle atau pemukul yang terbuat dari kayu, dilakukan oleh satu atau dua pemain yang saling berhadapan dalam lapangan berbentuk persegi empat yang dibatasi net pada bagian tengahnya dengan cara memukul bola untuk mengembaikan bola yang dipukul lawannya sampai salah satu pemain memenangkan reli dan game dengan memperoleh skor sesuai peraturan yang diberlakukan.

Permainan tonnis dimainkan dalam lapangan berbentuk segiempat dengan ukuran sama dengan 
lapangan bulutangkis, yaitu panjang 13,40 meter dan lebar 6,10 meter. Pada bagian tengah lapangan dibatasi dengan net yang tingginya $80 \mathrm{~cm}$ pada bagian tengah dan $85 \mathrm{~cm}$ pada bagian tiang net. Permukaan lapangan dapat berupa tanah liat, rumput atau lapangan keras yang terbuat dari bahan semen. Batasbatas lapangan ditandai dengan garis selebar $5 \mathrm{~cm}$ atau dari tali. Dengan demikian untuk membuat lapangan tonnis tidak perlu membutuhkan lahan atau ruangan yang cukup luas, seperti pada lapangan tenis, sehingga di seiap lingkungan masyarakat dimungkinkan dapat membuat lapangan tonnis.

Raket yang digunakan untuk memukul bola adalah paddle. Paddle ini dibuat dari bahan kayu yang ringan tetapi kuat atau tidak mudah patah, seperti papan multiplex dengan ketebalan 8-12 mm. Model pemukul ini dapat dibuat dalam berbagai bentuk dengan panjang keseluruhan $\quad 32 \quad \mathrm{~cm} \quad$ (panjang pegangan $8 \mathrm{~cm}$ dan bagian atas 24 $\mathrm{cm})$, dan lebar $20 \mathrm{~cm}$.

Bola untuk bermain tonnis menggunakan bola seukuran bola tenis pada umumnya tetapi memiliki tekanan udara yang sangat kurang atau gembos dan lebih ringan, dengan maksud agar pantulan bola tidak keras dan laju bolamenjadi lambat atau idak cepat seperti pada bola tenis biasa.

\section{Modifikasi Pembelajaran}

\section{Permainan Tonnis}

Modifikasi adalah salah satu upaya yang dapat dilakukan oleh para guru agar proses pembelajaran dapat berjalan secara maksimal. Modifikasi dapat diartikan sebagai upaya melakukan perubahan dengan penyesuaian-penyesuaian baik dalam segi fisik material maupun dalam tujuan.

$\begin{array}{lcc}\text { Tujuan } & \text { modifikasi } & \text { yang } \\ \text { dilakukan guru agar } & \text { siswa } \\ \text { memperoleh } & \text { kepuasan } & \text { dalam }\end{array}$
mengikuti pelajaran, meningkatkan kemungkinan keberhasilan pembelajaran, dan siswa dapat melakukan pola gerak secara benar.

Penerapan modifikasi harus dilakukan secara cermat karena apabila penerapan ini tidak sesuai maka hasil yang di dapat akan jauh dari apa yang kita harapkan. 


\section{Media Pembelajaran}

Media merupakan kata yang berasal dari bahasa latin "medius", yang secara harfiah berarti perantara atau pengantar. (Rudi Sisilana \& Cepi Riyana, 2009: 6). Oleh karena itu media dapat diartikan sebagai perantara atau pengantar pesan dari pengirim ke penerima pesan. Media dapat berupa sesuatu bahan, atau alat.

Media merupakan sarana pembelajaran yang digunakan untuk menyampaikan informasi kepada siswa yang bertujuan untuk membuat tahu siswa. Media adalah pembawa pesan yang berasal dari suatu sumber pesan (dapat berupa orang atau benda) kepada penerima pesan. Dalam proses pembelajaran penerima pesan itu adalah siswa. Pembawa pesan (media) itu berinteraksi dengan siswa melalui indera mereka. Siswa dirangsang dengan media itu untuk menggunakan inderanya untuk menerima informasi.

Media pembelajaran sangat berperan untuk keberhasilan proses belajar mengajar. Peranan media pembelajaran terutama adalah untuk membantu penyampaian materi kepada siswa. Dalam hal ini bisa terlihat bahwa tingkat kualitas atau hasil belajar juga dipengaruhi oleh kualitas media pembelajaran yang digunakan.

Untuk mendapatkan kualitas media pembelajaran yang baik agar dapat memberikan pengaruh yang signifikan dalam proses belajar mengajar, maka diperlukan pemilihan dan perencanaan penggunaan media pembelajaran yang baik dan tepat. Pemilihan media pembelajaran yang tepat ini menjadikan media pembelajaran efektif digunakan dan tidak sia-sia jika diterapkan.

\section{METODE}

Metode penelitian yang digunakan adalah Penelitian Tindakan Kelas.

Subjek yang diteliti dalam Penelitian Tindakan Kelas ini adalah peserta didik kelas IV SD Negeri Banyuanyar II Surakarta Tahun Ajaran 2017/2018 yang berjumlah sebanyak 36 peserta didik.

Teknik pengumpulan data dalam Penelitian Tindakan Kelas ini 
terdiri atas tes dan observasi. Tes digunakan untuk mendapatkan data tentang hasil belajar permainan tonnis. Sedangkan observasi digunakan sebagai teknik untuk mengumpulkan data tentang aktivitas yang dilakukan peserta didik dan guru selama proses pembelajaran.

\section{HASIL}

Hasil belajar peserta didik dalam pembelajaran permainan tonnis setelah tindakan siklus II dilakukan telah mencapai indikator pencapaian target dalam penelitian yaitu sebesar $75 \%$ dengan menunjukkan persentase ketuntasan sebesar 77,78\% sesuai dengan KKM mata pelajaran pendidikan jasmani di SD Negeri Banyuanyar II Surakarta yaitu 75. Dalam hal ini, sejumlah 28 peserta didik termasuk dalam kategori Tuntas sedangkan 8 peserta didik Belum Tuntas.

\section{PEMBAHASAN}

Berdasarkan hasil pelaksanaan tindakan pada Siklus I dan II dapat disimpulkan bahwa terjadi peningkatan Hasil Belajar permainan tonnis pada peserta didik kelas IV SD Negeri Banyuanyar II Surakarta tahun ajaran 2017/2018. Dari hasil analisis yang diperoleh peningkatan yang signifikan terjadi pada Pra Tindakan ke Siklus I dan dari Siklus I ke Siklus II. Pada Pra Tindakan hasil belajar permainan tonnis pada kategori Baik sebesar 5,56\%, Cukup sebesar 27,77\%, Kurang sebesar $52,78 \%$ dan Kurang Sekali sebesar 13,89\%. Jumlah peserta didik yang Tuntas adalah 12 peserta didik dan 24 peserta didik Belum Tuntas.

Pada Siklus I hasil belajar permainan tonnis telah menunjukkan peningkatan pada kategoriBaik Sekali sebesar 11,11\% Baik sebesar 41,67\%, Cukup sebesar 11,11\%, Kurang sebesar 13,89\% dan Kurang Sekali sebesar 22,22\%. Jumlah peserta didik yang Tuntas adalah 25 peserta didik dan 11 peserta didik Belum Tuntas. Kemudian pada Siklus II menunjukkan peningkatan pada kategori Sangat Baik sebesar 36,11\%, Baik sebesar 33,33\%, Cukup sebesar $8,33 \%$ dan Kurang Sekali sebesar 22,22\%. Jumlah peserta didik yang Tuntas adalah 28 peserta didik dan 8 peserta didik 
Belum Tuntas. Peningkatan terjadi pada Pra Tindakan ke Siklus I dan dari Siklus I ke Siklus II setelah diberikan tindakan berupa penerapan modifikasi media pembelajaran pada pembelajaran permainan tonnis. Pada siklus I hasil belajar permainan tonnis meningkat walaupun belum mencapai indikator pencapaian target dalam penelitian yaitu sebesar $75 \%$, hal ini disebabkan karena:

1. Peserta didik masih kurang berkonsentrasi pada materi dan masih sering bergurau dengan temannya.

2. Beberapa Peserta didik masih kurang serius karena suasana panas oleh terik matahari dan peserta didik selalu meminta minum terlebih dahulu..

Oleh karena itu, peneliti bersama guru penjas melakukan refleksi dan evaluasi dengan melakukan perbaikan rancangan pembelajaran pada siklus II yang berupa:

1. Penerapan tanya jawab setelah penyampaian materi agar peserta didik lebih memperhatikan dan berkonsentrasi terhadap materi.
2. Peneliti bersama guru selalu berusaha agar pembelajaran berjalan baik dan efektif sehingga meningkatkan proses pembelajaran gerak dasar permainan tonnis melalui modifikasi paddle, bola dan lapangan .

Pelaksanaan Siklus II membuat hasil belajar permainan tonnis meningkat menjadi lebih baik yaitu mencapai $77,78 \%$. Capaian ini sudah mencapai $\quad 75 \% \quad$ sehingga pembelajaran gerak dasar permainan tonnis menggunakan modifikasi paddle, bola, lapangan dan net dapat meningkatkan hasil belajar gerak dasar permainan tonnis, dalam hal ini pembelajaran gerak dasar permainan tonnis menggunakan modifikasi paddle, bola, lapangan dan net sangat baik dan cocok digunakan dalam proses pembelajaran karena siswa tidak mengeluh bosan dan lebih mudah dalam memukul bola sehingga efektif dalam proses pembelajaran. 


\section{SIMPULAN DAN SARAN}

\section{Simpulan}

Penelitian ini dapat

meningkatkan hasil pembelajaran permainan tonnis dikarenakan siswa yang sangat berantusias dalam mengikuti kegiatan belajar mengajar. Hal itu dapat dilihat pada hasil akhir siklus II yaitu siswa yang tuntas $77,78 \%$ yang artinya 28 siswa dari jumlah keseluruhan 36 siswa. Dan masih ada 22,22\% siswa belum tuntas.

Dengan demikian dapat disimpulkan bahwa penggunaan modifikasi media pembelajaran dapat meningkatkan hasil belajar permainan tonnis pada siswa kelas IV SD Negeri Banyuanyar II Surakarta tahun ajaran 2017/2018.

\section{Saran}

Sehubungan dengan simpulan yang telah diambil maka disarankan hal-hal sebagai berikut:

1. Bagi guru penjas SD, untuk meningkatkan hasil belajar permainan tonnis dengan menggunakan modifikasi media pembelajaran dan untuk peserta didik yang belum tuntas dalam materi permainan tonnis agar diberikan remedial teaching.

2. Bagi kepala sekolah hendaknya memberikan sarana dan prasaran yang lengkap pada mata pelajaran penjas, untuk menunjang kelancaran proses pembelajaran.

3. Bagi siswa, untuk meningkatkan hasil belajar permainan tonnis harus mengikuti pembelajaran dengan menggunakan modifikasi media pembelajaran. 


\section{DAFTAR PUSTAKA}

Ahmad Susanto. (2013).Teori Belajar Pembelajaran. Jakarta: Prenadamedia Aunurrahman. 2009. Belajar dan Pembelajaran. Bandung: Alfabeta Deni Kurniawan. 2014. Pembelajaran terpadu Tematik. Bandung: Alfabeta Giri Wiarto. 2016. Media Pembelajaran Dalam Pendidikan Jasmani. Yogyakarta M. Sobry Sutikno. 2009. Belajar dan Pembelajaran.Bandung: Holistica Samsudin. 2008. Pembelajaran Pendidikan Jasmani Olahraga dan Kesehatan $(S D)$. Jakarta: Prenada Media Group

Tri Nurharsono dan Sri Haryono. 2009. Permainan Tonnis. Semarang: UNNES 